\title{
Mechanisms of sucrose and non-nutritive sucking in procedural pain management in infants
}

\author{
Sharyn Gibbins RN Msc $\mathrm{PhD}^{1}$, Bonnie Stevens RN $\mathrm{PhD}^{2}$
}

\begin{abstract}
S Gibbins, B Stevens.
Mechanisms of sucrose and non-nutritive sucking in procedural pain management in infants.

Pain Res Manage 2001;6(1):21-28.
\end{abstract}

The administration of sucrose with and without non-nutritive sucking (NNS) has been examined for relieving procedural pain in newborn infants. The calming and pain-relieving effects of sucrose are thought to be mediated by endogenous opioid pathways activated by sweet taste. The orogustatory effects of sucrose have been demonstrated in animal newborns, and in preterm and full term human infants during painful procedures. In contrast to sucrose, the analgesic effects of NNS are hypothesized to be activated through nonopioid pathways by stimulation of orotactile and mechanoreceptor mechanisms. Although there is uncertainty as to whether the effects of sucrose and NNS are synergistic or additive, there is sufficient evidence to support the efficacy of combining the two interventions for procedural pain relief in infants. In this review article, the underlying mechanisms of sucrose and NNS, separately and in combination for relieving procedural pain in preterm and full term infants, are examined. Clinical and research implications are addressed.

Key Words: Infants; Mechanisms; Non-nutritive sucking; Pain; Sucrose

$\mathrm{N}$ ewborn infants hospitalized in neonatal intensive care units (NICUs) are subjected to many painful procedures during efforts to improve their clinical status. In one study (1), infants born between 27 and 31 weeks of gestation received a mean of 134 painful procedures within the first two weeks of life, and approximately $10 \%$ of the youngest and/or sickest infants received over 300 painful procedures.

\section{Mécanismes de l'administration du sucrose et de la succion non nutritive dans le traite- ment de la douleur associée aux interven- tions chez les enfants en bas âge}

RÉSUMÉ : L'administration du sucrose associée ou non à la succion non nutritive (SNN) pour soulager la douleur associée aux interventions chez les nouveau-nés a fait l'objet de recherche. Les effets calmants et analgésiques du sucrose seraient liés à la libération d'opioïdes endogènes, déclenchée par la saveur sucrée. Les effets orogustatifs du sucrose ont été démontrés chez des animaux nouveau-nés, ainsi que chez des nourrissons prématurés et nés à terme pendant des interventions douloureuses. Contrairement au sucrose, les effets analgésiques de la SNN seraient liés à l'activation des voies non opioïdes, déclenchée par la stimulation des mécanismes orotactiles et mécano-récepteurs. Même si l'incertitude règne quant aux effets du sucrose et de la SNN, à savoir s'ils sont synergiques ou complémentaires, il existe suffisamment de preuves pour appuyer l'efficacité de l'association des deux mesures pour soulager la douleur associée aux interventions chez les nouveau-nés. Le présent rapport de synthèse porte sur les mécanismes sous-jacents de l'administration du sucrose et de la SNN, appliquées seules ou en association, pour soulager la douleur associée aux interventions chez les enfants prématurés et nés à terme. Il est également question de la portée clinique et de l'incidence sur la recherche.

\footnotetext{
${ }^{1}$ Faculty of Nursing, University of Toronto, and ${ }^{2}$ Faculty of Nursing and Medicine, University of Toronto, Signy Hildur Eaton Chair in Paediatric Nursing
} Research, The Hospital for Sick Children, Toronto, Ontario

Correspondence: Ms Sharyn Gibbins, Sunnybrook \& Women's College Health Sciences Centre, 76 Grenville Avenue, Room 445, Toronto, Ontario

M5A 1B2. Telephone 416-323-7716, fax 416-323-6274, e-mail sharyngibbins@swchsc.on.ca 
evidence, clinicians and researchers need to identify safe and efficacious interventions to reduce the immediate and long term effects of procedural pain.

Sucrose is a disaccharide consisting of fructose and glucose. The soldiers of Alexander the Great, who entered India in $325 \mathrm{BC}$, first introduced sucrose to the West (38). In later centuries, the use of sucrose as a sweetening agent was spread by the Arabs and the Crusaders, and was introduced into the New World by Columbus in 1493. Today, sucrose is used as a common household sweetening agent. Compared with sucrose, the sweeteners fructose, glucose, maltose and lactose are 1.7, 0.75, 0.33 and 0.6 times as sweet, respectively (39). The soothing and calming properties of these agents have been anecdotally described by generations of parents and grandparents who claim that sweet tastes calm distressed infants. Current medicinal uses include sucrose in suspensions for oral medications, possibly to conceal the bitter taste of the pharmacological agent. These traditional uses of sucrose were not likely based on rigorous scientific study.

The administration of sucrose has been the most frequently studied nonpharmacological intervention for the relief of procedural pain in newborn infants. Sucrose has been shown to promote calming behaviours and reduce acute procedural pain in preterm and full term infants. The efficacy of sucrose for procedural pain in infants has been addressed in two systematic reviews $(40,41)$. In the first review (40), only one study with preterm infants $(\mathrm{n}=16)$ and four studies with full term infants $(\mathrm{n}=255)$ met the inclusion criteria for a meta-analysis. The primary outcome in the meta-analysis was the proportion of crying time during the 3 min after the painful stimulus. Sucrose doses greater than $0.24 \mathrm{~g} \mathrm{(} 2 \mathrm{~mL}$ of $12 \%$ weight/volume [w/v] sucrose) given orally by syringe or pacifier approximately 2 min before a painful stimulus were the most effective in decreasing cry duration. In some studies, heart rate, facial expressions and composite assessments of pain were also decreased. There were no significant clinical benefits of administering doses greater than $0.50 \mathrm{~g}$. In the second systematic review (41), smaller doses of sucrose were shown to be effective in decreasing more specific physiological and behavioural pain responses in preterm and full term infants. However, the optimal dose of sucrose to reduce procedural pain could not be identified because methodological and conceptual limitations in the studies prevented accurate comparisons. Across studies, there were differences in the definition of pain, painful stimuli, delivery method of sucrose, pain outcomes and study methods.

Non-nutritive sucking (NNS) is the provision of a pacifier or nonlactating nipple into an infant's mouth to promote sucking behaviours without the provision of breast milk or formula for nutrition. Caregiver activities such as positioning, rocking, swaddling and holding, and providing pacifiers have been used for many years to calm infants and provide comfort during painful and stressful events. Pacifiers are readily available in NICUs and have been reported by NICU nurses as the first choice of pain relieving intervention (42). Providing NNS has reduced behavioural pain responses during circumcision $(28,43,44)$, immunizations $(45,46)$, mechanical ventilation $(47)$ and heel lances in full term $(48)$ and preterm infants $(1,49)$. Composite pain scores were also reduced in preterm infants who received NNS during heel lances (1). Pain relief was further reduced in infants who received NNS and sucrose in combination.

Compared with swaddling (22) or rocking (49) during painful procedures, NNS reduces the duration of crying and soothes infants more rapidly. However, unlike swaddling, there is a rebound in distress when the pacifier is removed from the infant's mouth. The efficacy of NNS is immediate but terminates almost immediately upon cessation of sucking. In a systematic review (50), the efficacy of NNS for many infant outcomes, including weight gain, energy intake, heart rate, oxygen saturation, transition to oral/nipple feedings and length of hospitalization in NICUs, was evaluated. The primary outcome selected for the review was length of stay. Preterm infants who were provided with a pacifier during gavage feedings were discharged from hospital earlier than preterm infants who were not provided with NNS. The review did not reveal any other benefits of NNS, but infants were not followed past discharge. Although family members, as well as health care professionals, have historically used NNS, very little rigorous research exists to determine the efficacy of NNS for procedural pain relief.

In summary, although there is evidence to support the efficacy of sucrose and NNS for the management of pain in preterm and full term infants, the mechanisms underlying the efficacy of these interventions have not been clearly delineated. In the present review, the individual and combined mechanisms of sucrose and NNS are examined, and the most likely hypotheses are proposed.

\section{Animal research}

\section{MECHANISMS OF SUCROSE}

The effectiveness of sweet tasting substances in reducing pain responses was initially derived from animal models (51-53). In rat pups, milk infusion, corn oil, polycose and sucrose have increased paw-lift latency and decreased the number of ultrasonic distress vocalizations in response to thermal pain (54). Conversely, water infusions did not affect lift-paw latency or vocalizations. Sweet taste-induced analgesia, however, was altered in the presence of opioid antagonists such as naltrexone and high levels of competing sweet tastes. Rat pups receiving intraoral saccharine for 28 consecutive days did not respond to exogenous morphine treatment for painful thermal stimuli. Furthermore, the pain responses were not affected by the administration of naltrexone (55). Therefore, although the efficacy of sweet tastes appears to provide opioid-mediated analgesia in the rat model, repeated doses of sweet tastes may result in tolerance to subsequent opioid administration. Further research to examine this hypothesis is required.

Several different hypotheses regarding the underlying mechanisms of sucrose exist; however, there is one hypoth- 
esis that is the most plausible and has the most support. The sweet taste of sucrose is proposed to promote analgesia through activation of endogenous opioids that attenuate nociceptive information at the level of the dorsal horn (56). Rat pups preferentially ingested sucrose over milk and other nonsweet solutions during painful and stressful events (57). Rat fetuses that received intrauterine injections of apple juice preferentially ingested apple juice over milk 15 days after birth. Compared with control rats, rats that received intrauterine apple juice consumed greater amounts of apple juice (58). These data indicate that rat fetuses can discriminate tastes and that memory of tastes exists after birth. Opioids also appear to enhance feeding and food choice. In particular, fat and sweet consumption increases with the administration of opioids and is suppressed by opioid antagonists $(59,60)$. The relationship among dietary choice, taste preference and the modulation of pain appears to be opioidmediated.

\section{Human research}

Because of ethical reasons, much of what has been studied in animal models cannot be replicated with human infants. Therefore, although the efficacy of sucrose is reduced in animal models in the presence of high levels of endogenous opioids, the relationship in human infants remains theoretical. In one study, pain responses of post-term infants were compared with those of healthy full term infants (61). Term infants were significantly more calmed by sucrose, as measured by cry duration, than were post-term infants $(\mathrm{P}<0.01)$. The authors hypothesized that the release of $\mathrm{B}$ endorphins associated with postmature infants resulted in tolerance to sucrose. Similar to animal models, high levels of endogenous opioids appear to alter responsiveness to sucrose (55). In a second study involving term infants $(n=4)$, infants born to mothers who were maintained on methadone during their pregnancy were used to draw comparisons between endogenous opioids and responsiveness to sucrose (48). Infants of mothers exposed to methadone were not calmed by sucrose. Furthermore, sucrose did not prevent these infants from becoming agitated when a pacifier to promote NNS was removed. Although the sucrose was taken avidly, the infants only stopped crying when the pacifier was returned to their mouth or the infant placed his or her hand into the mouth. Sucrose also failed to reduce the infant's physiological stress responses associated with crying (heart rate). These preliminary data suggest that the mechanisms underlying sucrose and NNS are likely different.

Taste receptors that detect sweetness are found at the anterior tip of the tongue, where sucrose is administered. Taste receptors are evident in human infants by the end of the eighth week of gestation, and sensory nerve fibres from the receptors of the tongue to the brainstem are established by 26 to 28 weeks' gestation (62). Taste fibres unite in the medulla oblongata, where they synapse with fibres for touch, pain and temperature (55). Impulses are then relayed to the cerebral cortex for interpretation. In preterm, full term and older infants, sweet tastes are preferred over fats, pro- teins, lactose and water $(48,63)$. Sucrose preference, as measured by intake, was related to sweetness in all age groups (48). Rank ordering of sugars by adults was shown to be identical to that of infants, with sucrose preferred over fructose, which is preferred over glucose, which is preferred over lactose (64). Similar to animal models, adults, and full term and older infants preferentially ingest sweets or fats over nonsweets when stressed; this relationship is probably opioid mediated. Responses to nonsweet tastes during stressful situations are similar across age groups and include raised cheeks and narrowed or tightly closed eyes, wrinkled nose and eyebrows pulled together (65). Conversely, responses to sweet tastes include facial relaxation, handmouth behaviours and sucking.

Taste-induced analgesia in animal $(52,57)$ and human (62-67) newborns is rapid, enduring and dependent on the ability to detect sweet taste. Only trace amounts of sucrose have been detected chemically in saliva within $1 \mathrm{~min}$ after administration (48). Term infants who receive small amounts of sucrose remain in awake and alert states, and place their hands in their mouths. Hand-mouth behaviours only appear after crying stops - disputing the argument that crying only stops because it is incompatible with handmouth or sucking behaviours.

Sucrose has been administered to preterm, full term and older infants by syringes $(17,18,68,69)$, droppers (70), drinks $(67,71)$ or on pacifiers $(1,63,71)$. In one study $(71)$, different routes of sucrose administration were compared in preterm infants. In a crossover design, including two consecutive heel lances, infants received randomly allocated sterile water or sucrose before the first heel lance. The solution was given through a nasogastric tube, which passed directly into the stomach. For the second heel lance, the infant received the same solution via syringe onto the tongue. Pain responses were measured by behavioural pain scores comprised of facial expressions (brow bulge, eye squeeze, nasolabial furrow and open mouth). Compared with sterile water, sucrose administered directly on the tongue significantly reduced crying time and behavioural pain scores. Neither sucrose nor sterile water delivered directly into the stomach via the nasogastric tube reduced responses to procedural pain. Sucrose is hydrolyzed into glucose and fructose through the intestinal epithelium, which is present, by 26 weeks' gestation $(38,72,73)$. Given the rapid effects of intraoral sucrose, it is unlikely that hydrolysis in the small intestine is responsible for its painrelieving properties.

A variety of sucrose concentrations $(7.5 \%, 12 \%, 24 \%$ and $50 \%$ ), volumes and administration schedules have been implemented to reduce procedural pain in newborn infants. Sucrose has calmed infants as early as $9 \mathrm{~h}$ after birth, and the calmness persisted 5 to $10 \mathrm{~min}$ after a painful stimulus (48). Various time delays between sucrose intake and the initiation of painful procedures have been used $(40,41,67)$. Reductions in crying time have been found $2 \mathrm{~min}$ after sucrose is administered onto the tongue. A 2 min interval appears to be required for taste receptors in the mouth to 
mediate opioid responses and inhibit nociceptive impulses. When duration of cry was used as an indicator of pain, $0.24 \mathrm{~g}$ sucrose ( $2 \mathrm{~mL}$ of $12 \% \mathrm{w} / \mathrm{v}$ sucrose) is efficacious for heel lances $(10,68,69)$ and venepunctures $(18)$ in preterm infants, and heel lances $(63,66,70)$ in term infants, but not for circumcision (74), eye examinations (75) or intramuscular injections (45). Although there is a trend toward a reduction in crying time with greater concentrations of sucrose (76), no benefit to administering doses greater than $0.5 \mathrm{~g}$ has been found. A few researchers $(1,68,69)$ have reported that very small doses of sucrose $(0.12 \mathrm{~g})$ reduce composite pain scores comprised of heart rate, respiratory rate and facial expressions in infants less than 34 weeks of gestation. However, these smaller doses of sucrose are not efficacious in full term infants and do not appear to be sustained in older infants (45).

Age and maturation appear to decrease the efficacy of sucrose. Sucrose administered to full term infants (32) before a heel lance reduced crying by $40 \%$ compared with water, but did not reduce crying in older infants. Similarly (45), sucrose reduced crying time in two-week-old infants during immunizations but did not reduce crying in infants older than two months of age. In a multiple regression analysis that included age, infant condition and time required for a nurse to perform immunization, age of the infant at the time of data collection was the only variable that predicted percentage of crying, with younger infants crying longer. The age effect may be related to the time when other behavioural and environmental interventions such as eye-to-eye contact, distraction, relaxation, swaddling or positioning, or co-coordinated NNS are implemented.

In summary, existing studies on the efficacy of sucrose in human neonates have incorporated varying doses, painful procedures and pain outcomes. Although the variability of data and study methods prevents meaningful conclusions, it appears that the sweet taste of sucrose detected on the tongue 2 min before a painful procedure is the mechanism by which opioid responses are mediated in preterm and full term infants. Sucrose is readily taken by preterm and full term infants; however, its efficacy as a pain-relieving intervention decreases with age and maturation. Other factors related to the administration of the intervention, such as dose and concentration, may alter the magnitude of pain responses, but they are unlikely to be responsible for mediating the endogenous opioid response. Perhaps once a threshold of sucrose concentration or volume has been crossed, all volumes and concentrations are equally efficacious in reducing pain (48).

\section{MECHANISMS OF NNS}

The calming effects of NNS have been observed in human and rat neonates, but the mechanisms underlying its effectiveness remain unclear. NNS is thought to produce analgesia in human infants through stimulation of orotactile and mechanoreceptors when a pacifier or nonlactating nipple is introduced into the infant's mouth (48). Unlike the mechanisms of sucrose, the orotactile-induced analgesia associ- ated with NNS does not appear to be mediated through opioid pathways; it is not affected by the administration of naltrexone, and its efficacy is terminated once sucking has ceased.

In rat neonates, orotactile stimulation with a nonlactating anesthetized dam to promote NNS has been found to decrease distress vocalization associated with thermal pain. Rat pups at 10 days of age showed delayed withdrawal latencies from heat when NNS was provided (77). Relative to isolated rats, rats lying in contact with other rats doubled their heat-withdrawal latencies. Rats provided with NNS increased their heat-escape latencies by four times, while rats positioned in hyperextension and allowed to receive milk infusion did not withdraw from thermal pain at all. Unlike the heat-escape latencies in the isolated or contact groups, the pain relief associated with NNS was not blocked by large doses of naltrexone or norbinaltorphimine. In addition, morphine added to the pain-relieving effects in the contact group but multiplied the effects in the NNS and sucking/feeding groups. Suckling pups given morphine had increased heat-escape latencies by $15 \mathrm{~min}$, and the effects were observed for $60 \mathrm{~min}$. Contact or isolated rats did not achieve maximum latency for $45 \mathrm{~min}$, and the effects were not observed by $60 \mathrm{~min}$. These notions suggest that the effects of NNS, although not opioid mediated, may potentiate the effects of opioid analgesics. Research examining synergism between NNS and opioids is required.

Limited data are available to support the underlying mechanisms of NNS as a pain-relieving intervention. However, there are several possible mechanisms underlying efficacy. The gate control theory (78) purports that pain impulses travel from the periphery to the central nervous system (CNS) by ascending pathways in the spinal cord. Impulses are modulated via descending pathways from the CNS by a 'gating' mechanism at the level of the spinal cord. Analgesia likely occurs at the level of the dorsal horn. Interventions such as distraction and relaxation may reduce arousal during and after painful procedures $(79,80)$; however, they have only been evaluated to a limited extent with respect to infant pain management. Other cognitive therapies such as patient education, anticipatory guidance, coping strategies and imagery are not possible for use with infants. Physical strategies such as environmental modification and/or reduction of bright light, noise and frequent handling may reduce infant pain by reducing excessive and cumulative noxious stimuli and promoting behavioural state stability, but limited data exist. NNS is widely used to calm infant pain because of relative ease and accessibility. NNS may reduce pain responses by inhibiting nociceptive impulses from the periphery along the ascending fibres or activating tactile afferent fibres that stimulate the descending influencing systems to close the 'gate' and reduce pain.

The involvement of serotonergic systems in the modulation of pain is well documented in the management of adult pain $(81,82)$. Serotonin and serotonin reuptake inhibitors appear to facilitate the release of B endorphins. In contrast, serotonin receptor blockers cause significant decreases in 
B endorphins (83). Previous data suggest that $B$ endorphins play a role in analgesia in post-term infants (61). Serotoninmediated analgesia, as measured by B endorphin levels, is observed when serotonin and serotonin reuptake inhibitors are injected into the arcuate nucleus and nucleus accumbens of adult rats (83). Compared with control rats, rat pups that had had a surgical transection of their serotonergic system had decreased B endorphins despite injections of serotonin or serotonin reuptake inhibitors. The ability to relieve pain appears to be related to neuronal reuptake of serotonin. In the rat model, intracerebroventricular boluses of serotonin reuptake inhibitors decreased pain responses associated with subcutaneous injections of formaldehyde, thermal pain and neuropathic pain created by tight ligation of spinal nerves. The pain inhibitory effects of serotonin and serotonin reuptake inhibitors were prevented by injection of serotonergic antagonists. However, the inhibitory effects were not prevented by the opioid antagonist naloxone. These results indicate that serotonin provides analgesia through nonopioid mechanisms.

A systematic review (81) comprised 19 studies that examined the efficacy of serotonin reuptake inhibitors for the management of pain. Although none of the studies included infants or children, serotonin reuptake inhibitors consistently reduced chronic pain associated with headaches, diabetic neuropathy, postherpetic neuralgia and fibromyalgia. No data on acute procedural pain exist, but studies with animals have indicated that pain responses to mechanical stimuli are reduced with selective serotonin reuptake inhibitors (83-86).

There is some evidence that the serotonergic system promotes calming through attachment and suckling behaviours $(85,86)$. In one animal study, serotonin reuptake inhibitors reduced the frequency of rat pups detaching and re-attaching to a non-lactating anesthetized dam (85). There was a trend for a dose-related decrease in re-attaching behaviours with larger doses. Serotonin reuptake inhibitors also decreased the frequency of nipple switching and increased the time spent attached to the nonlactating breast. Serotonin reuptake inhibitors did not increase suckling behaviours when weight gain was used as a proxy for suckling. Control rats had significantly more weight gain than rats that received serotonin. Weight gain may not be a valid indicator of suckling.

Similar results were found when serotonin receptor blockers, which prevent the neuronal reuptake of serotonin, were injected into rat pups (86). Serotonin receptor blockers increased the percentage of suckling in rat pups between 10 and 25 days. These agents also reinstated suckling behaviours in weaned pups. Rats younger than 10 days of age all suckled, regardless of whether they received serotonin or saline. Similar to the previous study (86), serotonin reuptake inhibitors did not increase suckling behaviours in rats older than 35 days. However, these older rats were more settled than the control group. The age-related differences might reflect developmental maturation of the serotonin system, whereby younger rats have immature serotonergic systems and older rats may have other mechanisms that contribute to the abandonment of suckling at weaning. These data support the hypothesis that serotonin modulates attachment behaviours to a nipple, similar to NNS, but does not appear to influence suckling, which is associated with ingestion. Further research to examine possible mechanisms for serotonin mediation, in the absence of feeding, is required.

In vitro brainstem-spinal cord preparations from newborn rats have been used to locate the area in the brain responsible for sucking reflexes (87). A rhythmical suckinglike activity of the hypoglossal nerve as the index of sucking was used, and a fluorescent dye was injected. The induced sucking action persisted after removal of the dorsal medulla oblongata, the caudal pons and trigeminal spinal nucleus. The researchers concluded that the central rhythm generator for sucking is localized in the ventromedial medulla oblongata. Stimulation to the central rhythm generator was derived from only sucking. Further research to clearly identify the area responsible for sucking is required.

In summary, NNS temporarily reduces the physiological and behavioural responses to procedural pain and promotes calmness in preterm, full term and older infants. The mechanisms underlying the efficacy of NNS remain unclear, but unlike sucrose do not appear to be mediated through opioid systems. It is hypothesized that stimulation associated with sucking mediates the production of serotonin that contributes to immediate but transient analgesia. The fibre stimulation associated with continuous, rhythmic sucking may explain why the efficacy of NNS dissipates within $30 \mathrm{~s}$ of sucking termination (88). Unlike the efficacy of orogustatory-induced analgesia, which endures several minutes after sucrose is administered, NNS does not have lingering effects. Further research of the role of NNS and production of serotonin is required.

\section{COMBINED MECHANISMS OF SUCROSE AND NNS}

In an attempt to understand better the interaction of sucrose and NNS, Blass and Watt (88) examined 40 full term infants undergoing heel lances. Infants randomly received sucrose alone, water alone, pacifier with water (NNS), or pacifier with sucrose. Sucking movements were recorded in real time and quantified during the treatment phase. NNS with sucrose was more effective - as measured by cry duration, grimace and heart rate changes - than NNS or sucrose alone. NNS was analgesic when the suck rate exceeded 32 sucks/min. The authors suggested that antinociceptive mechanisms associated with NNS are engaged when sucking thresholds have been reached. Infants with fewer than 30 sucks/min were also comforted during the treatment phase. However, these infants received the combination of sucrose and NNS. The authors further suggested that the orotactile threshold previously described does not have to be reached if orogustatory mechanisms associated with sucrose taste are activated. Unlike NNS, the pain-relieving effects associated with sucrose persisted long after the painful stimulus had terminated. 
Stevens and colleagues (1) examined the combined efficacy of sucrose and NNS for relieving procedural pain in preterm infants. Each infant received four interventions in random order: prone positioning, a pacifier dipped in water, a pacifier dipped in $24 \%$ sucrose or standard care (containment and side-lying position). Behavioural and physiological responses were used to calculate a composite pain score. Significant differences in pain scores between the pacifier with water and control group $(\mathrm{P}<0.005)$, and pacifier with sucrose and control group $(\mathrm{P}<0.0001)$ were found. There was a trend $(\mathrm{P}<0.05)$ toward lower pain scores with the sucrose and NNS group compared with the water and NNS group.

The comforting and pain-relieving behaviours observed with the combination of sucrose and NNS may be similar to behaviours observed during breastfeeding. Mothers initially calm their agitated infant by orotactile or body contact (48). The calming associated with warmth, positioning and containing is immediate and thereby allows the infant to locate and attach to the nipple. The infant stops crying and remains in a quiet and attentive state to obtain sufficient milk for satiation. The cessation of crying, reduced heart rate, gross motor movements and calm state associated with orotactile stimulation with the nipple are required for infant feeding. Following the orotactile stimulation with the nipple, the infant draws milk from the breast by rhythmic, sucking behaviour. Infants are further calmed after milk is detected through orogustatory stimulation (47). It is hypothesized that the orotactile mechanism associated with nipple attachment is transferred to the orogustatory mechanisms where opioid mediation occurs. To date, few investigators have evaluated the efficacy of breastfeeding or breast milk for reducing pain during painful procedures. Ors and colleagues (89) randomly assigned 102 healthy term infants to receive $2 \mathrm{~mL}$ of $25 \%$ sucrose, human milk or sterile water $2 \mathrm{~min}$ before heel lancing. Crying time, median recovery time and the percentage change in heart rate were significantly lower in the group that received sucrose than in the groups that received human milk or sterile water. Similarly, Skogsdal et al (90) randomly assigned 120 newborns infants to receive no treatment, $1 \mathrm{~mL}$ of $30 \%$ glucose, $10 \%$ glucose or breast milk $2 \mathrm{~min}$ before heel lance. Significant reductions in crying and heart rate increases were noted in the group that received $30 \%$ glucose. Therefore, although the mechanisms for sucking may be similar in nutritive and non-nutritive sucking, the effectiveness of breast milk as an analgesic, based on these limited data, has not yet been supported.

\section{CLINICAL IMPLICATIONS}

Sucrose and NNS have potential clinical benefits because they are readily available in hospital nurseries, are inexpensive, are easily administered and have few known risks. The combination of sucrose and NNS has both calming and pain-relieving properties and, therefore, can be used for a variety of diagnostic and therapeutic activities that are painful. Given the rapid and enduring effects of sucrose and NNS, they can be given together in advance of minor to moderate procedural pain. In addition, pharmacological interventions can be used as an adjunct with the combined therapy for severe acute or chronic pain.

Both sucrose and NNS have been used safely for single painful procedures in animal and human preterm, full term and older infants. Only one study (91) has suggested that sucrose administration predisposes preterm infants to necrotizing enterocolitis, but the lack of methodological rigour within the study precludes any supportable conclusions. Many pathogenetic mechanisms such as prematurity, alteration of bowel flora, presence of umbilical lines or nasogastric route of administration may contribute to necrotizing enterocolitis. No other data concerning the safety of NNS are available. Although sucrose and NNS appear to be safe, further study is required to determine tolerance, potential risks and safety.

\section{RESEARCH IMPLICATIONS}

There are sufficient animal data to draw parallels to human infants; sucrose appears to be mediated through endogenous opioid pathways, and the mechanism underlying efficacy is sweet taste. However, the mechanisms underlying NNS remain unclear, and although a few animal studies suggest that multiple pathways including contact, vestibular or serotonergic pathways may be involved, there are insufficient data to draw comparisons with human infants. Further research identifying the role of sucking in relation to serotonin production in animals is required. In addition, research examining possible feedback mechanisms between sucking and further production of serotonin may explain the rapid but transient analgesic properties of NNS. Data from animal models can then be used to infer mechanisms of NNS in human infants.

Sucrose and NNS are safe for single painful procedures, but no studies have examined the use of the interventions alone or in combination for repeated painful stimuli in a heterogenous population such as extremely low birth weight or neurologically impaired infants. Similarly, no data on chronic infant pain-relieving interventions are available. Researchers conducting the meta-analyses on sucrose and NNS were not able to identify the most efficacious dose of sucrose for a variety of gestational ages or painful procedures. Prospective randomized, controlled trials with a validated composite measure of pain and a sufficient sample size to detect significant clinical and statistical differences are required.

The efficacy of sucrose appears to decrease with age and maturation. Studies using sucrose with other environmental and behavioural interventions such as positioning, skin to skin contact or visual/auditory stimuli may be combined to improve pain management for older infants. The efficacies of sucrose and NNS appear to be synergistic rather than additive; the presence of one therapy accentuates the action of the other therapy. Although both interventions are efficacious as analgesics, the magnitude and duration of effect are enhanced with combined therapy, although the magnitude of the enhancement has not been well delineated. Animal data indicate that morphine adds to the pain-relieving effects of 
contact but multiplies the effects of NNS. Efficacy of the interventions for infant pain relief may be similar, but prospective, randomized, controlled trials that examine each intervention alone and in combination for specific painful stimuli are needed.

\section{CONCLUSIONS}

The frequency of acute procedural pain in NICUs and the potential for immediate and long term detrimental effects of pain necessitate the need for safe, efficacious and clinically effective interventions to reduce procedural pain in infants. Sucrose appears to be antinociceptive, mediated through endogenous opioid systems, effective with a short latency and effective after the painful stimulus has ceased. The mechanisms underlying sucrose appear to be orogustatory. In contrast, the mechanisms underlying NNS are unclear but probably involve orotactile receptors that stimulate serotonin production. NNS is not mediated through opioid pathways; efficacy is transient and not affected by opioid antagonists.

Sucrose and NNS are efficacious for rat pups, and preterm and full term human infants. The combination of sucrose and NNS involves both opioid and nonopioid pathways and, therefore, offers the most potent nonpharmacological intervention for procedural pain. The common use of sucrose in the human diet and the frequent use of pacifiers to calm infants from earliest times suggest that there are few concerns over adverse effects. Although the combination of orogustatory and orotactile-induced analgesia is not sufficient for severe pain, these interventions can be incorporated into clinical practice and used with other pharmacological or nonpharmacological interventions in a multifocused pain-relieving strategy. Further research on the underlying mechanisms to explain the efficacy of sucrose and NNS for repeated or chronic pain is required.

ACKNOWLEDGEMENTS: We gratefully acknowledge the financial support of The Hospital for Sick Children, Toronto, Ontario, Canada for the Research Training Award (Sharyn Gibbins) and the Ontario Ministry of Health, Toronto, Ontario, for the Career Scientist Award (Bonnie Stevens). We also acknowledge Drs Ellen Hodnett, Janet Pinelli, and Arne Ohlsson (PhD thesis committee members for Sharyn Gibbins) and Dr Dorothy Pringle for their support and critique of this work.

\section{REFERENCES}

1. Stevens B, Johnston C, Franck L, Petryshen P, Jack A, Foster G. The efficacy of developmentally sensitive interventions and sucrose for relieving procedural pain in very low birth weight neonates. Nurs Res 1999;48:35-42.

2. Anand KJS, Carr DB. The neuroanatomy, neurophysiology and neurochemistry of pain, stress and analgesia in newborns and children. Pediatr Clin North Am 1989;36:795-822.

3. Anand KJS, Phil D, Hickey PR. Halothane-morphine compared with highdose sufentanil or anesthesia and postoperative analgesia in neonatal cardiac surgery. N Engl J Med 1992;326:1-9.

4. Meyer RA, Campbell JN, Raja SN. Peripheral neural mechanisms of nociception. In: Anand KJS, McGrath PJ, eds. Pain in Neonates. Amsterdam: Elsevier Science, 1993:13-37.

5. Besson J, Chaouch A. Peripheral and spinal mechanisms of nociception. Physiol Rev 1987;67:67-181.

6. Fitzgerald M. Neurobiology of fetal and neonatal pain. In: Anand KJS, McGrath PJ, eds. Pain in Neonates. Amsterdam: Elsevier Science, 1993:153-61.

7. Fitzgerald M, Anand KJS. Developmental neuroanatomy \& neurophysiology of pain. In: Schechter N, Berde DB, eds. Pain in Infants, Children and Adolescents. Baltimore: Wilkins, 1993:11-32.

8. Anand KJS, Hickey PR. Randomized trial of high-dose sufentanil aesthesia in neonates undergoing cardiac surgery; Effects on the metabolic stress response. Anesthesiology 1987;67:502A. (Abst)

9. Guinsburg R, Kipelman B, Anand K, Branco M, Peres C, Miyoski M. Physiological, hormonal and behavioral responses to a single fentanyl dose in intubated and ventilated preterm neonates. J Pediatr 1998;132:854-9.

10. Bucher H, Moser T, Von Siebenthal K, Keel M, Wolf M, Duc G. Sucrose reduces pain reaction to heel lancing in preterm infants: A placebocontrolled, randomized and masked study. Pediatr Res 1995;38:332-6.

11. Craig K, Whitfield MF, Grunau RV, Linton J, Hadjistavropoulos H. Pain in the preterm neonate: behavioral and physiological indices. Pain 1993;52:287-99.

12. Franck L. A new method to quantitatively describe pain behavior in infants. Nurs Res 1986;35:28-31.

13. Owens ME, Todt EJ. Pain in infancy: neonatal reaction to a heel lance. Pain 1984;20:77-84.

14. Porter F, Wolf C, Miller P. The effect of handling and immobilization on the response to acute pain in newborn infants. Pediatrics 1998;102:1383-9.

15. Stevens B, Petryshen P, Hawkins T, Smith B, Taylor P. Developmental care versus conventional care: A comparison of clinical outcomes for very low birth weight infants. Can J Nurs Res 1996;28:97-113.

16. Johnston C, Stevens B. Experience in a neonatal intensive care unit affects pain response. Pediatrics 1996;98:925-30.

17. Ramenghi L, Wood C, Griffeth G, Levene M. Reduction of pain response in premature infants using introral sucrose. Arch Dis Child 1996;74:F126-8.

18. Abad F, Diaz N, Domenech E, Robayna M, Rico J. Oral sweet solution reduces pain-related behavior in preterm infants. Acta Paediatr 1996;85:854-8

19. Anand KJS. The biology of pain perception in newborn infants. In: Tyker DC, Krane EI, eds. Advances in Pain Research. New York: Raven Press, 1990:113-21.

20. Anand KJS, Craig KD. New perspectives on the definition of pain. Pain 1996;67:3-6.

21. Stevens B, Johnston C. Physiological responses of preterm infants to a painful stimulus. Nurs Res 1994;43:226-31.

22. Campos R. Soothing pain elicited distress in infants. Child Dev 1989;60:781-92.

23. Field T, Goldson E. Pacifying effects of non-nutritive sucking on term and preterm neonates during heelstick procedures. Pediatrics 1984;74:1012-25.

24. Grunau RV, Johnston CC, Craig KD. Neonatal facial and cry responses to invasive procedures and non invasive procedures. Pain 1990;42:295-305.

25. Craig K. The facial display of pain in infants and children. In: Finley GA, McGrath PJ, eds. Measurement of Pain in Infants and Children in Pain Research and Management, vol 10. Seattle: IASP Press, 1998:103-21.

26. Evan S, Vogelpohl D, Bourguignon C, Morcott C. Pain behaviors in LBW infants accompany some nonpainful caregiving procedures. Neonatal Network 1997;16:33-9.

27. Grunau RV, Craig KD. Facial activity as a measure of neonatal pain expression. In: Tyler DC, Krane EJ, eds. Advances in Pain Therapy and Research, vol 15. New York: Raven Press, 1990:147-56.

28. Marchette L, Main R, Redick E. Pain reduction during neonatal circumcision. Pediatr Nurs 1989;15:207-10.

29. Porter FL, Miller RJ, Marshall RE. Neonatal pain cries: Effect of circumcision on acoustic features and perceived urgency. Child Dev 1986;57:790-808.

30. Schoen EJ. Sucrose as an analgesic for newborn infants. Pediatrics 1991;88:1287-8.

31. Grunau RV, Craig KD. Pain expression in neonates: facial action and cry. Pain 1987;28:395-410.

32. Barr RG, Quek VS, Cousineau D, Oberlander TF, Brian JA, Young SN. Effects of intra-oral sucrose on crying, mouthing and hand-mouth contact in newborn and six-week-old infants. Dev Med Child Neurol 1994;36:608-18

33. Carraccio C, Feinberg P, Hart L, Quinn M, King J, Lichenstein R. Lidocaine for lumbar punctures. Arch Pediatr Adolesc Med 1996;150:1044-6.

34. Fitzgerald M. Development of pain mechanisms. Br Med Bull 1991;47:667-75. 
35. Taddio A, Goldbach M, Ipp M, Stevens B, Koren G. Effect of neonatal circumcision on pain responses during vaccination in boys. Lancet 1995;345:291-2.

36. Grunau RV, Whitfield MF, Petrie JH, Fryer EL. Early pain experience, child and family factors, as precursors of somatization: A prospective study of extremely premature and fullterm children. Pain 1994;56:353-9.

37. Grunau RV, Whitfield MF, Petrie JH. Pain sensitivity and termperament in extremely low birth weight premature toddlers and preterm and full-term controls. Pain 1994;58:343-6.

38. Neu J, Koldovsky O. Nutrient absorption in the preterm neonate. Clin Perinatol 1996;23:229-41.

39. Martindale W. The Extra Pharmacopoeia, 29th edn. London: Pharmaceutical Press, 1989:1275.

40. Stevens BJ, Taddio A, Ohlsson A, Einarson T. The efficacy of sucrose for relieving procedural pain in neonates - a systematic review and metaanalysis. Acta Paediatr 1997;86:837-42.

41. Stevens B, Ohlsson A. The efficacy of sucrose to reduce procedural pain in neonates as assessed by physiologic and/or behavioral outcomes. In: Sinclair JC, Bracken MB, Soll RS, Horbar JD, eds. Neonatal Modules of the Cochrane Data Base of Systematic Reviews. Oxford: The Cochrane Library, 1998.

42. Franck LS. A national survey of the assessment and treatment of pain and agitation in the neonatal intensive care unit. J Obstet Gynecol Neonatal Nurs 1987; 16:387-93.

43. Blass E, Hoffmeyer LB. Sucrose as an analgesic for newborn infants. Pediatrics 1991;87:215-20.

44. Zahorodny W, David E, Estrada P, Co J, Marshall R. Efficacy of sucrose pacifier for newborn pain. Pediatric Academic Societies' Annual Meeting, San Francisco, May 1-4, 1999. (Abst)

45. Allen K, White D, Walburn J. Sucrose as an analgesic agent for infants during immunization injections. Arch Pediatr Adolesc Med 1996;150:270-4.

46. Schanler R. Suitability of human milk for the low birthweight infant. Clin Perinatol 1995;22:207-19.

47. Miller H, Anderson S. Nonnutritive sucking: Effects on crying and heart rate in intubated infants requiring assisted mechanical ventilation. Neonatal Intensive Care 1994;7:46-8.

48. Blass E, Ciaramitaro V. A new look at some old mechanisms in human newborns: taste and tactile determinants of state, affect and action. Monogr Soc Res Child Dev 1994;59:1-80.

49. Campos RG. Rocking and pacifiers: Two comforting interventions for heelstick pain. Res Nurs Health 1994;17:321-31.

50. Pinelli J, Symington A. Non nutritive sucking in premature infants. In: Sinclair JC, Bracken MB, Soll RS, Horbar JD, eds. Neonatal Modules of the Cochrane Data Base of Systematic Reviews. Oxford: Cochrane Library, 1998.

51. Kehow P, Blass EM. Behaviorally functional opioid systems in infant rata; II. Evidence for pharmacological, physiological and psychological mediation of pain and stress. Behav Neurosci 1986;10:624-30.

52. Blass E, Shide D. Some comparisons among the calming and pain relieving effects of sucrose, glucose, fructose and lactose in infant rats. Chem Senses 1994;19:239-49.

53. Panksepp J, Siviy S, Normansell L. Brain opioids and social emotion. In: Reite M, Fields T, eds. The Psychobiology of Attachment and Separation. San Diego: Academic Press, 1986:3-39.

54. Shide D, Blass E. Opioid-like effects of intraoral infusions of corn oil and polycose on stress reactions in 10 day old rats. Behav Neurosci 1989;103:1168-75.

55. Lieblich IL, Cohen E, Ganchrow J. Morphine tolerance in genetically selected rats induced by chronically elevated saccharine intake. Science 1983;221:871-3.

56. Ganong W. Review of Medical Physiology. Toronto: Appleton \& Lange, 1995.

57. Blass E, Fitzgerald E. Milk induced analgesia and comforting in 10 day old rats: Opioid mediation. Pharmacol Biochem Behav 1988;29:9-13.

58. Stickrod G, Kimble D, Smothrman W. Methioine 5-enkephalons on associations formed in utero. Peptides 1982;3:881-3.

59. Marks-Kaufman R. Increased fat consumption induced by morphine administration in rats. Pharmacol Biochem Behav 1982;16:949-55.

60. Apfelbaum M, Mandenoff A. Naltrexone suppresses hyperphagia induced in the rat by a highly palatable diet. Pharmacol Biochem Behav 1981;15:89-91.

61. Smith BA, Stevens K, Torgerson WS, Kim J. Diminished reactivity of postmature human infants to sucrose compared with term infants. Dev Psychol 1992;28:811-20.

62. Moore K. The Developing Human, 4th edn. Toronto: WB Saunders, 1988. 63. Graillon A, Barr R, Young S, Wright J, Hendricks L. Differential response to intraoral sucrose, quinine and corn oil in crying human newborns. Physiol Behav 1997;62:317-25.

64. Blass E, Smith B. Differential effects of sucrose, fructose, glucose and lactose on crying in 1-3 day old human infants; Qualitative and quantitiative considerations. Dev Psychol 1992;28:804-10.

65. Rosenstein D, Oster H. Differential facial responses to four basic tastes in newborns. Child Dev 1988;59:1555-68.

66. Blass E. Milk-induced hypoalgesia in human newborns. Pediatrics. 1997;99:825-9.

67. Blass E, Shah A. Pain reducing properties of sucrose in human newborns. Chem Senses 1995;20:29-35.

68. Johnston CC, Stremler RL, Stevens BJ, Horton LJ. Effectiveness of oral sucrose and simulated rocking on pain response in preterm neonates. Pain 1997;72:193-9.

69. Johnston CC, Stremler RL, Horton LJ, Friedman A. Effect of repeated doses of sucrose during heel stick procedure in preterm neonates. Biol Neonate 1999; 75:160-6.

70. Rushforth JA, Levene MI. Behavioural response to pain in healthy neonates. Arch Dis Child 1993;70:174-6.

71. Ramenghi LA, Evans DJ, Levene MI. Sucrose analgesia: Absorptive mechanism or taste perception? Arch Dis Child Fetal Neonatal Ed 1999;80:F146-7.

72. Aldoretta PW, Hay W. Metabolic substrates for fetal energy metabolism and growth. Clin Perinatol 1995;22:15-33.

73. Kien C. Digestion, absorption and fermentation of carbohydrates in the newborn. Clin Perinatol 1996;23:211-23.

74. Naqui M, Biskinis E, Khattack I. Effects of $50 \%$ sucrose on pain responses in full term male infants during circumcision. Pediatric Academic Societies' Annual Meeting. San Francisco, May 1-4, 1999. (Abst)

75. Pearson C, Jorgenson K, Blocker R, Bauchner H, Mirochnick M. Reducing the pain of neonatal eye examination: A randomized controlled trial of plain and sugar dipped pacifier. Pediatric Academic Societies' Annual Meeting. San Francisco, May 1-4, 1999. (Abst)

76. Haouari N, Wood C, Griffiths G, Levene M. The analgesic effect of sucrose in full term infants: A randomized controlled trial. Br Med J 1995;310:1498-500.

77. Blass EM, Shide DJ, Zaw-Mon C, Sorrentino J. Mother as shield: differential effects of contact and nursing on pain responsivity in infant rats: evidence for nonopioid mediation. Behav Neurosci 1999;109:342-53.

78. Melzack R, Wall PD. Pain mechanisms: A new theory. Science 1965;150:971-9.

79. Corff K. An effective comfort measure for minor pain and stress in preterm infants: Facilitated tucking. Neonatal Netw 1993;12:74.

80. Corff KE, Seideman R, Venkataraman PS, Lutes L, Yates B. Facilitated tucking: A non pharmacologic comfort measure for pain in preterm infants. J Obstet Gynecol Neonatal Nurs 1995;24,143-47.

81. Jung A, Staiger T, Sullivan M. The efficacy of selective serotonin reuptake inhibitors for the management of chronic pain. J Gen Intern Med 1997;12:384-9.

82. Max M. Treatment of post-herpetic neuralgia: antidepressants. Ann Neurol 1994;35(Suppl):S50-3.

83. Wang YX, Bowersox SS, Pettus M, Gao D. Antinociceptive properties of fenfluramine, a sertonin reuptake inhibitor, in a rat model of neuropathy. J Pharmacol 1999;292:1008-16.

84. Zangen A, Nakash R, Yadid G. Serotonin-mediated increases in the extracellular levels of beta endorphin in the arcuate nucleus and nucleus accumbens: a microdialysis study. J Neurochem 1999;73:2569-74.

85. Spear LP, Frambes NA, Goodwin GA, Moody C. The 5-HT1A agonist 8-OH-DPAT increases attachment maintenance but decreases suckling-related intake in 17-18 day old rat pups. Pharmacol Biochem Behav 1994;47:133-9.

86. Williams C, Rosenblatt JS, Hall WG. Inhibition of suckling in weaning-age rats: a possible serotonergic mechanism. J Comp Physiol Psychol 1979;93:414-29.

87. Jia L. Localization of central rhythm generator for tongue movements in sucking: analysis of isolated brainstem-spinal cord preparation from newborn rats. Kodubyo Gakkai Zasshi 1997;64:499-511.

88. Blass E, Watt L. Suckling and sucrose induced analgesia in human newborns. Pain 1999;82:1-13.

89. Ors R, Ozek E, Baysoy G, et al. Comparison of sucrose and human milk on pain response in newborns. Eur J Pediatr 1999;15:63-6.

90. Skogsdal Y, Eriksson M, Schollin J. Analgesia in newborns given oral glucose. Acta Paediatr Scand 1997;86:217-20.

91. Willis DM, Chabot J, Radde IC, Chance GW. Unsuspected hyperosmolarity of oral soultion contributing to necrotizing entercolitis in very low birth weight infants. Pediatrics 1977;60:535-8. 


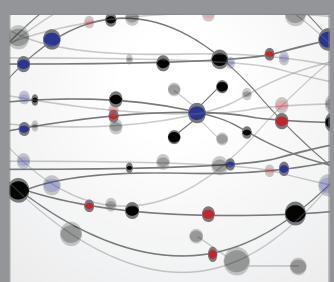

The Scientific World Journal
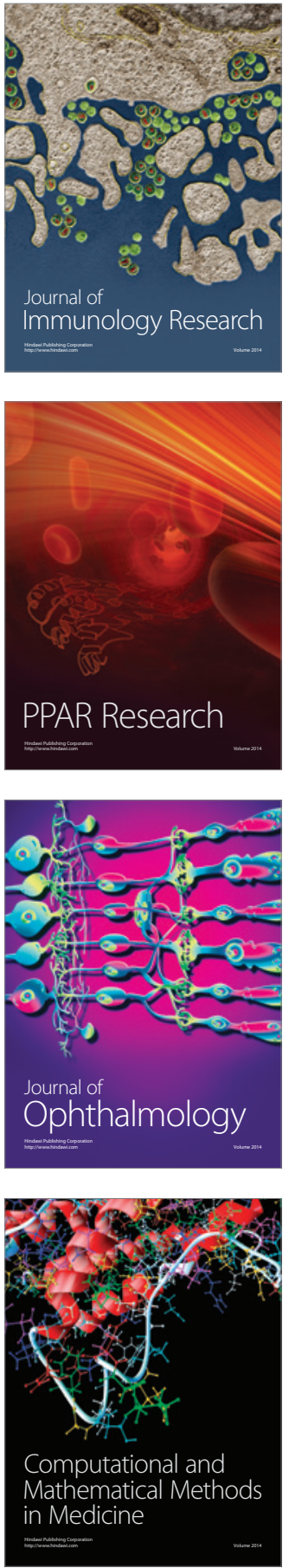

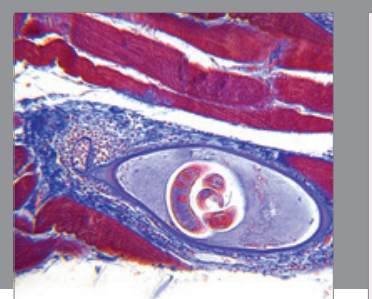

Gastroenterology Research and Practice

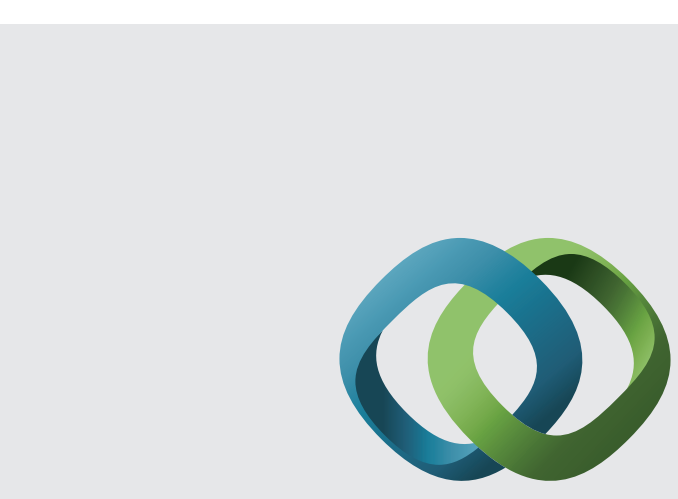

\section{Hindawi}

Submit your manuscripts at

http://www.hindawi.com
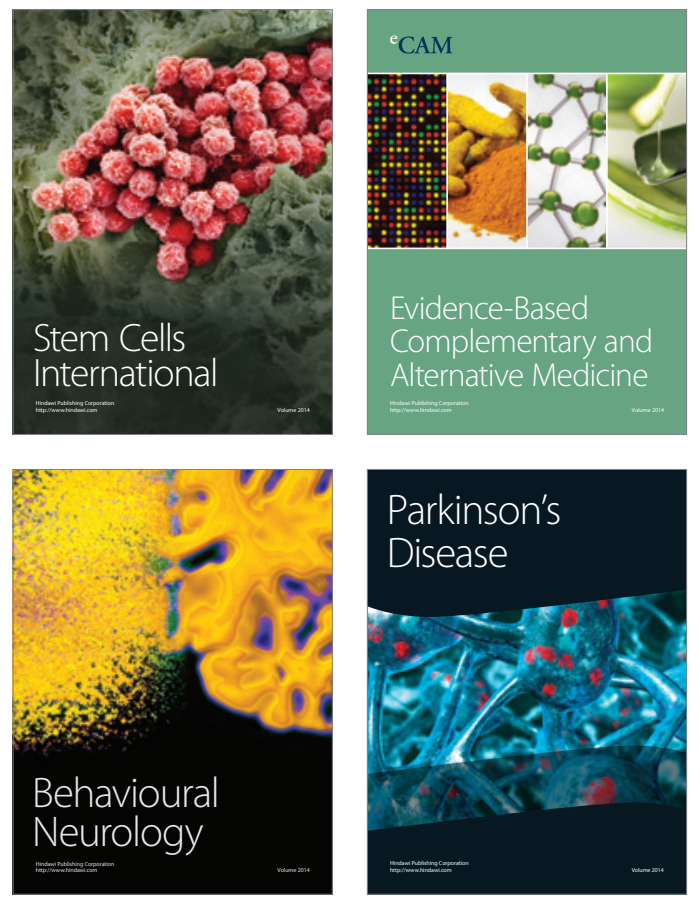
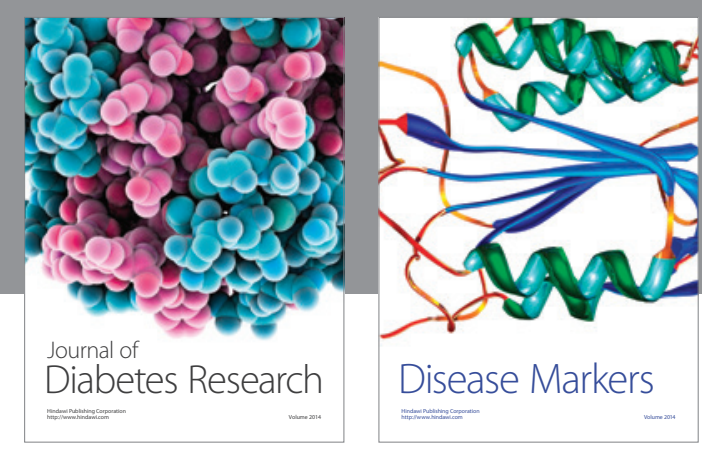

Disease Markers
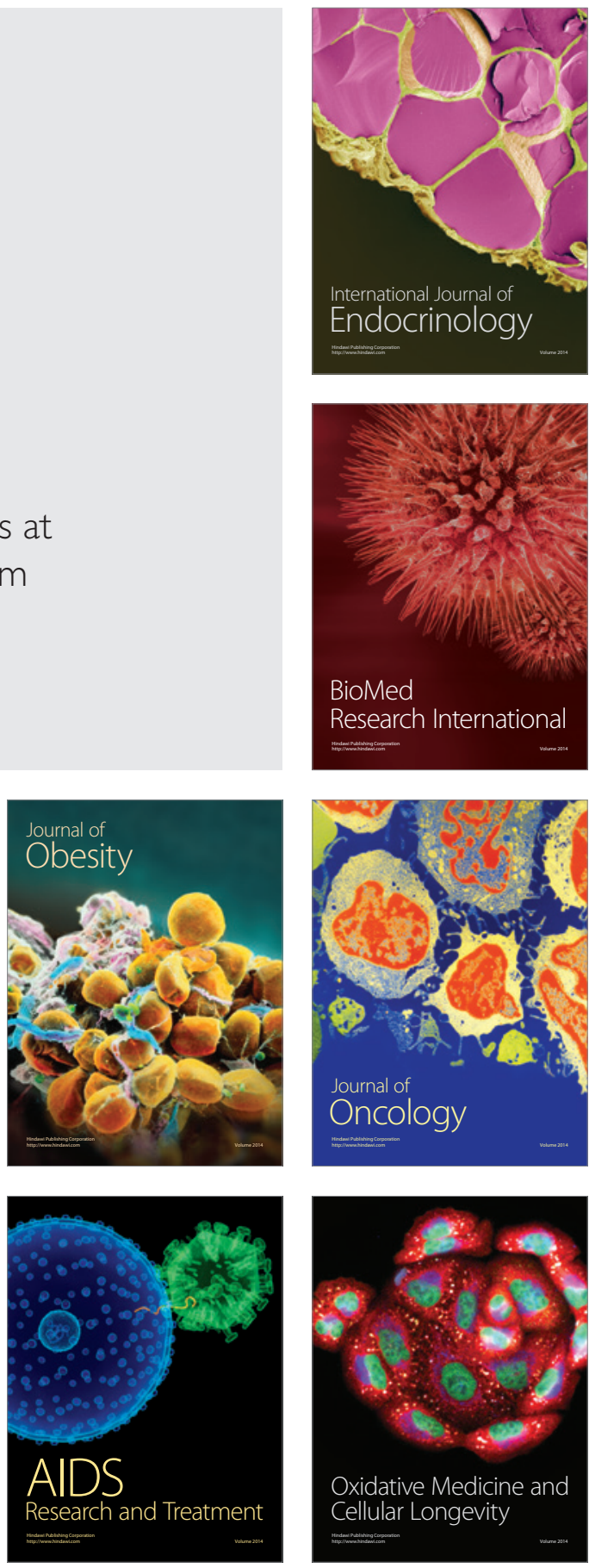